\title{
The West gropes for ways to help
}

\section{Washington}

SHORING up science in the former Soviet Union will be a long and expensive process that will require inventive new forms of international collaboration. But not doing so, say Soviet emigré scientists now living and working in the United States, could mean the loss of an entire generation of scientists in those newly freed countries.

What to do about this vast pool of talent was the subject of a special session at the annual April meeting of the American Physical Society last week. Like other scientific organizations, the APS is searching for ways to help the thousands of FSU scientists whose research budgets have been cut in half and who are facing further reductions as their governments try to stave off economic chaos.

A great deal is already happening. The National Science Foundation, for example, has recently offered an extra $\$ 10,000$ to 100 US scientists from various disciplines who are already receiving NSF support for collaborative projects with researchers in the former Soviet Union. The money can go toward anything from scientific equipment and office supplies to subscriptions and shipping. It does not cover salaries. If NSF had more money, says programme officer Gerson Sher, it would like to extend such supplemental awards to any recipient of an NSF grant with a worthwhile idea for joint research.

The Stanford Linear Accelerator Center is waiting for approval from the US Department of Energy for a $\$ 10,000$ subcon- tract that will allow it to support some 20 theoretical physicists at the Physical Technical Institute in St Petersburg. The agreement is the latest to take advantage of the bargain-basement salaries that Russian scientists earn compared with their Western colleagues. In other cases, individual researchers have been remarkably successful after taking matters into their own hands (see accompanying story).

Everyone agrees that such time-honoured responses as travel fellowships and free copies of journals, although important, will not solve the problem. There is also consensus that the aid should by-pass the ex-Soviet bureaucracy and go directly into the hands of individuals. At its core, the issue comes down to the question asked during the APS meeting by Herman Feshbach of the Massachusetts Institute of Technology: "How do we identify the people we want to help?"

The answer, it seems, will require the research establishments in both the United States and the countries of the former Soviet Union to adopt new approaches to supporting talent. And there were plenty of suggestions of how to bring that about.

"Think of those groups with the most promising futures", said Edward Shuryak, a theoretical high-energy physicist at the State University of New York, Stony Brook, who arrived in the United States two years ago from Novosibirsk. "Ask them to put together proposals that US scientists can look at. Then give them small grants, and invite the best ones over for a better look."
At the same time, Shuryak predicted that the enormous difference in the exchange rate between the ruble and the dollar will not last forever, and he warned his colleagues not to start something that they cannot finish. "It will be more expensive in the long run to support scientists than it now appears", he said. "You must take that into account."

Efforts to aid such scientists must also find ways to deal with the large gap that exists between younger researchers and senior scientists who are already wellknown in the West, according to Mark Strikman of Pennsylvania State University, formerly of St Petersburg. A successful programme, he believes, must involve both age groups.

"At Penn State we are trying to create small centers of four or five people," Strikman says. "It would be led by a senior scientist visiting from Russia, who would attract a rotating group of visitors. People would stay long enough to develop US contacts and then go back to Russia."

Such 'shuttle science', now being conducted at several universities, exposes scientists in the former Soviet Union to the Western approach to science funding, including a crash course on grant writing, peer review and other aspects of conducting science in a market economy. And, although not perfect, it works surprisingly well. As one former Soviet scientist now working in the United States pointed out, "You'd be surprised how quickly people learn on an empty stomach".

Jeffrey Mervis

\section{US astronomers compute an answer}

AstRoPHYSICIST Rashid Sunyaev is getting by with a little help from his friends. Sunyaev and his team of 600 scientists and technicians at the Institute for Space Research (IKI) in Moscow have worked for five years to prepare a massive $X$-ray and gamma-ray satellite for launch in 1995. It is an international effort, with researchers from France, Britain, the Netherlands and the United States providing half a dozen instruments that will be launched on a Proton rocket.

With two previous highenergy physics missions under its belt - one, Kvant, was launched serendipitously only a month before the explosion of the $1987 \mathrm{~A}$ supernova and detected $\mathrm{X}$-ray emissions from it - the IKI team has won the respect of astronomers around the world. But its ability to analyse data from Kvant and GRANAT (a gamma-ray telescope launched in 1989) missions, much less to handle the 1-gigabit-a-day output of the forthcoming satellite, has been limited by its available computing power, a handful of antiquated IBM-PC clones.

Enter Don Lamb, an astrophysicist at the University of Chicago and a long-time colleague of Sunyaev. Lamb is not a member of the team for the Spectrum X-Gamma mission, but when he learned in January of Sunyaev's dilemma he vowed to do something about it. "I told Rashid that one way or the other I would make it happen."

One thing he did was to call Bob Novick, a physicist at
Columbia University who is principal investigator on one of the instruments and a member of the mission's international scientific council, and Jerry Ostriker, an astrophysicist at Princeton with strong links to the Russian space science community. Within a few weeks, each of them had persuaded his university to contribute $\$ 8,000$ towards the purchase of modern workstations.

In the midst of his campaign, Lamb talked with Roald Sagdeev, the former director of IKI, who was visiting Chicago as part of the university's celebration of its 100 th anniversary and who had been talking to officials from Sun Microsystems Company about ways they could help FSU scientists. Soon Lamb was talking on the telephone with Jordan Graham, European marketing manager for Sun, which had just opened an office in Moscow.

Sun more than doubled the university's contribution to the Russian space institute by donating nearly $\$ 30,000$ worth of equipment. The resulting package - three colour SPARC workstations with 19-inch colour monitors, 8 megabytes of memory and several other features, plus a CD ROM reader and a high-speed tape backup drive - was shipped to Moscow for a computer exhibition in early April. The IKI scientists, after being trained by Sun, simply took the equipment with them at the end of the show.

J.M. 